\title{
A relação entre o risco de expropriação de acionistas minoritários e os níveis diferenciados de governança corporativa
}

\section{The relationship between the risk of expropriation of minority shareholders and differentiated corporate governance}

\section{Mirian Mara Batista da Silva}

Universidade Federal de Minas Gerais (UFMG)

email:mirian.marab@gmail.com

\section{Laura Edith Taboada Pinheiro}

Universidade Federal de Minas Gerais (UFMG) email: Itaboada@face.ufmg.br

\section{Fernanda Alves Cordeiro}

Universidade Federal de Minas Gerais (UFMG)

email:fernandaest@yahoo.com.br

\section{RESUMO}

Esta pesquisa objetivou investigar se os níveis diferenciados de governança corporativa impactam na redução do risco de expropriação de acionistas minoritários das empresas listadas na B3 no período de 2010 a 2016. Como na literatura nacional e internacional se observa a mensuração da expropriação de minoritários através de variáveis isoladas, estas proxies foram relacionadas e agrupadas, através de Análise Fatorial, em quatro índices de expropriação. Foi realizado um teste de médias de Mann-Whitney, na amostra composta por 192 empresas divididas em Tradicional e nos níveis diferenciados de governança corporativa. As evidências deste estudo permitem concluir que o enquadramento das empresas em níveis diferenciados da B3 não é fator imprescindível para menor exposição ao risco de expropriação, mas uma vez que organizações pertencem a tais níveis há sugestão do decréscimo deste risco à medida que aumenta o nível de governança, exceto para o índice de intangibilidade.

Palavras-Chave: Risco de expropriação de acionistas minoritários; Governança Corporativa; Concentração acionária.
This research aimed to investigate corporate governance indicators with an impact on the expropriation of companies listed in B3 between 2010 and 2016. As the national and international literature shows the measurement of the expropriation of minority shareholders through variables The goals were related and grouped, through the Factorial analysis, in four expropriation indexes. Media analysis of Mann-Whitney, on the sample has been translated to 192 companies separately in the common and different classifieds of corporate governance. For such a study, B3 is not an essential factor for less exposure to the risk of expropriation governance, except for the intangibility index.

Key-words: Risk of expropriation of minority shareholders; Corporate governance; Stockholding concentration. 


\section{INTRODUÇÃO}

O processo de globalização e de desenvolvimento do mercado acionário impõe às empresas que buscam confirmar sua continuidade e sustentabilidade no mundo dos negócios, um bom relacionamento com os acionistas e demais partes envolvidas nas instituições. Consequências negativas para a eficiência da economia em geral são geradas pelo mau funcionamento do mercado de ações decorrente da estrutura de propriedade, conflito de interesses entre proprietários e gestores, falta de transparência e a atitude nem sempre correta com os acionistas minoritários (SILVA et al, 2009).

Segundo Young et al. (2008) nas economias desenvolvidas, visto que a propriedade e o controle são frequentemente separados e os mecanismos legais protegem os interesses dos proprietários, os conflitos que recebem maior atenção são referentes à principal e agente, porém, os pesquisadores em Finanças e Economia vêm percebendo cada vez mais que a tradicional teoria de conflitos de principal-agente não explica as realidades dos problemas entre principal-principal, ou seja, entre acionistas controladores e minoritários, que dominam as economias emergentes. Sendo assim, nestes países, os conflitos entre principal e principal têm sido identificados como uma grande preocupação da governança corporativa.

Em consonância com esse entendimento, a procura por um sistema de governança hábil a alinhar os interesses de acionistas majoritários, gestores e minoritários é apontada como uma das questões centrais do problema principal-principal, uma vez que protegeria os acionistas minoritários limitando os abusos de controladores quanto à utilização de benefícios privados (BRANDÃO; CRISÓSTOMO, 2015).

Sendo assim, este trabalho tem o seguinte problema de pesquisa: Empresas em elevados níveis de Governança Corporativa possuem menor índice de risco de expropriação de acionistas minoritários? Esta pesquisa tem como objetivo geral investigar a relação existente entre os diferenciados níveis de Governança Corporativa e o risco de expropriação de acionistas minoritários das empresas listadas na Brasil, Bolsa e Balcão - B3 no período de 2010 a 2016.

Os resultados deste estudo são relevantes para a academia por apresentar determinantes de expro- priação de acionistas minoritários mais robustos, e também para o mercado por evidenciar empiricamente o comportamento do risco de expropriação nos diferentes níveis de governança corporativa e também, nos casos de não adesão aos mesmos.

\section{FUNDAMENTAÇÃO TEÓRICA}

\subsection{Conflitos de agência e expropriação de acionistas minoritários}

A falta de consenso de interesses entre acionistas e gestores pode gerar problemas nas organizações tais como investimentos em projetos prejudiciais à saúde financeira da empresa, baixo incentivo dos indivíduos na busca de operações capazes de elevar o desempenho da firma, entre outros. Os exemplos citados evidenciam atitudes de uma minoria voltada à maximização de desejos particulares em detrimento de decisões que beneficiariam a empresa como um todo, demonstrando conflito de agência e consequentemente expropriação de acionistas minoritários, uma vez que os recursos utilizados para custear tais "privilégios" saem do caixa da instituição.

De acordo com Leal, Silva e Valadares (2002) compreender a estrutura de controle é fundamental, pois a mesma evidencia o nível de diversificação do risco e do tipo de problema de agência a que os acionistas possivelmente estarão expostos.

A relação de agência é definida por Jensen e Meckling (1976) como um contrato onde o proprietário (principal) delega autoridade ao gestor (agente) para realização de serviços em seu nome. Se os envolvidos nesta relação são maximizadores de utilidade, pode-se acreditar que nem sempre, o agente agirá segundo os interesses do principal. Surge então, o problema de agência denominado principal-agente uma vez que os acionistas tenderão a monitorar, de forma incompleta os gestores, para que os mesmos não utilizem mais benefícios que os acordados anteriormente.

O principal problema de agência na maioria dos países em desenvolvimento, de acordo com Javid e Iqbal (2008), não é o conflito entre gestores e sim, o risco de expropriação pelos acionistas dominantes ou controladores em detrimento dos minoritários. 
Nesse contexto de conflito de interesses, a Governança Corporativa se apresenta como uma ferramenta capaz de trabalhar tais divergências buscando a maximização de valor da empresa em geral e não de alguns acionistas.

\subsection{Governança Corporativa}

O Instituto Brasileiro de Governança Corporativa (2014, p.20) define Governança Corporativa (GC) como "o sistema pelo qual as empresas e demais organizações são dirigidas, monitoradas e incentivadas, envolvendo os relacionamentos entre sócios, conselho de administração, diretoria, órgãos de fiscalização e controle e demais partes interessadas".

Segundo Cavalcante e De Luca (2013, p.75) incorporando uma extensa base conceitual, a Governança Corporativa tem sido conceituada como um método de atuação "que envolve questões relacionadas às estruturas de controle e poder nas organizações, o papel do conselho de administração das empresas, a criação de valor para o acionista e o papel das corporações na sociedade".

A GC foi relacionada ao tema de expropriação de acionistas minoritários como demonstrado nos estudos de Silveira, 2004; Malacrida e Yamamoto, 2006; Nardi e Nakao, 2008; Barbedo, Silva e Leal, 2009; De Luca et al., 2010; Do Monte et al., 2010; e Forti, Peixoto e Alves, 2015.

Para Silveira (2004) os inúmeros casos de expropriação da riqueza dos acionistas, tanto em ambientes pulverizados quanto concentrados, salientaram a necessidade de aperfeiçoamento das práticas de governança nas empresas.

Para De Luca et al. (2010, p. 107) o enquadramento às regras de boa governança corporativa "contribui para a redução de custos de capital, agregando valor às sociedades, ao proporcionar mecanismos mais efetivos para consolidar negócios competitivos, e elevando o nível de confiança entre os acionistas e os potenciais investidores". Estes autores destacam que o objetivo do surgimento da governança corporativa foi criar mecanismos capazes de controlar e monitorar o comportamento dos gestores internos e acionistas, vislumbrando identificar e resolver os conflitos de agência que vierem a ocorrer.
De acordo com Do Monte et al. (2010) as boas práticas de Governança Corporativa podem ser utilizadas como instrumento para minimizar a incerteza relacionada aos retornos esperados por parte dos investidores, oriundos de uma decisão de investimento. Corroborando com esse entendimento, Nardi e Nakao (2008) destacam que Governança Corporativa é um assunto que se relaciona a todos os contextos possíveis em uma empresa, abrangendo acionistas, empregados, fornecedores, conselhos, entre outros. Acrescentam ainda que a criação dos níveis diferenciados de governança (Nível 1, Nível 2 e Novo Mercado) foi motivada principalmente pela mudança na imagem institucional da corporação, gerada pela credibilidade obtida cumprimento das rígidas regras de adesão, no intuito de minimizar as incertezas dos investidores e demais interessados.

A B3 instituiu os Níveis Diferenciados de Governança Corporativa (NDGC) para estimular e preparar paulatinamente, as empresas para ingressarem no Novo Mercado. Devido às boas práticas de governança, as empresas que aderem tais níveis, se beneficiam da redução de custos de capital, além do acréscimo de valor obtido pela elevação do grau de confiança dos acionistas (MALACRIDA; YAMAMOTO, 2006).

Ressalta-se que depois da implantação dos NDGC, as empresas ao emitirem novas ações, deveriam escolher por um desses níveis. Para as organizações que já possuíam o capital aberto, desde que não emitam novas ações, a adesão é voluntária (CAMARGOS; BARBOSA, 2010).

Segundo Procianoy e Verdi (2009, p.111) “a principal inovação do Novo Mercado, em relação à legislação, é a exigência de que o capital social da companhia seja composto somente por ações ordinárias." Percebe-se que o grau de exigência aumenta progressivamente entre os níveis diferenciados da Bovespa, sendo o Novo Mercado voltado às corporações interessadas pela adoção de melhores práticas de governança.

Cabe enfatizar que de acordo com Forti, Peixoto e Alves (2015), o simples fato da empresa não ser adepta dos níveis de governança diferenciados da Bovespa não significa que a mesma exclui as práticas de boa governança da sua gestão. Dessa forma, apenas a presença nos NDGC pode não ser indício de menor risco de expropriação. E o contrário também é 
verídico, ou seja, conforme Barbedo, Silva, Leal (2009, p.50) ainda que a adesão às boas práticas de governança seja um forte indicador do nível de proteção do investidor, a mesma não é capaz de conceder "uma medida objetiva da probabilidade de que o investidor venha a ser efetivamente expropriado."

\section{METODOLOGIA}

Este trabalho se classifica como descritivo com abordagem quantitativa, uma vez que procura investigar o comportamento do risco de expropriação de acionistas minoritários em relação aos níveis diferenciados de governança corporativa, por meio de métodos estatísticos.

A amostra desta pesquisa foi composta por 192 empresas não financeiras, de diversos setores, listadas na B3 no período de 2010 a 2016, constantes na base de dados Quantum. Foram excluídas da quantidade inicial (351) as empresas com observações faltantes (43), o que é determinado pelo fato de que a ausência dessas observações traria prejuízo à análise estatística dos dados utilizados e também, aquelas que não possuíam controlador definido (42), além das do setor Financeiro e Outros (74), pelo fato de divergirem das demais empresas em relação as proxies utilizadas no trabalho.

\subsection{Abordagem Estatística}

\subsubsection{Análise Fatorial}

Visando obter o índice de expropriação de acionistas minoritários, foi feito um levantamento na literatura para que a análise se baseasse em variáveis já utilizadas para mensuração de tal fenômeno conforme evidenciado no Quadro 1.

Na sequência foi analisada a correlações dessas proxies de expropriação de acionistas minoritários e aplicada a análise fatorial, pelo fato desta técnica multivariada, segundo Rencher (2002) minimizar a redundância entre as variáveis por meio da utilização de um menor número de fatores. De acordo com Mingoti (2005) na presença de uma grande quantidade de variáveis correlacionadas entre si, a análise fatorial poderia ser usada para apontar novas variáveis não correlacionadas, denominadas fatores ou variáveis latentes, em número reduzido, capazes de condensar as informações relevantes das variáveis originais.

\subsubsection{Teste de Médias}

A fim de analisar o comportamento do risco de expropriação em função dos diferentes níveis de governança corporativa, foi realizado um teste de médias. Assim, as empresas da amostra foram divididas em Tradicional e nos níveis N1, N2 e Novo Mercado e foi feita a comparação do risco de expropriação

Quadro 1 Variáveis construtivas do índice de risco de expropriação de acionistas minoritários

\begin{tabular}{c|c|l|l|c}
\hline Num. & Siglas & \multicolumn{1}{|c|}{ Variável } & \multicolumn{1}{c|}{ Autor (Ano) } & $\begin{array}{c}\text { Sinal } \\
\text { Esperado }\end{array}$ \\
\hline 1 & EMPC & Empréstimos contraídos pelos controladores & Jiang, Lee e Yue (2010) & $(+)$ \\
\hline 2 & EMPD & Empréstimos contraídos por elementos diversos & Jiang, Lee e Yue (2010) & $(+)$ \\
\hline 3 & TPR & Transações entre partes relacionadas & Friti, Irianto e Mardiati (2017) & $(+)$ \\
\hline 4 & DIV & Dividendos & Faccio, Lang e Young (2001) & $(-)$ \\
\hline 5 & DVFC & Fluxo de Caixa e Direitos de voto & Doidge et al (2009) e Renders e Gaeremynck (2012) & $(+)$ \\
\hline 6 & AC & Acionista Controlador & Brandão e Crisóstomo (2015) & $(+)$ \\
\hline 7 & ESTAT & Controle Estatal & Luo e Jackson (2012) & $(+)$ \\
\hline 8 & ESTRANG & Controle Estrangeiro & Tam e Tan (2007) & $(-)$ \\
\hline 9 & INTANG & Intangibilidade & Himmelberg, Hubbard e Palia (1999) & $(+)$ \\
\hline
\end{tabular}

Fonte: Elaboração própria 
em relação à governança, para confirmar ou não, a existência de diferenças significativas.

A verificação da adequabilidade do teste de médias foi pelo Teste de Mann Whitney, uma vez que é apropriado para amostras não paramétricas, como os dados desta pesquisa.

O teste de normalidade utilizado nesta pesquisa foi o de Jarque-Bera.

\section{ANÁLISE E DISCUSSÃO DOS RESULTADOS}

\subsection{Estatística Descritiva}

As variáveis que compõem os índices de risco de expropriação de acionistas minoritários das empresas constantes neste trabalho apresentam-se na Tabela 1 com suas estatísticas descritivas:

Na Tabela 1 verifica-se que a variável Dividendos (DIV) apresenta o menor valor médio, fato que pode ser explicado pela ausência de distribuição de dividendos por parte de um número considerável de empresas constantes na amostra (595 das 996 observações). De acordo com La Porta et al. (2000), os valores não distribuídos por dividendos podem ser usados em projetos economicamente não rentáveis aos minoritários e os resultados indicam que as organizações não utilizam a política de dividendos como mecanismo de minimização do conflito de agência.
Em contrapartida, a variável TPR destaca-se pela maior média, reforçando o vultuoso montante envolvido nas operações entre partes relacionadas, o que pode ser confirmado pelo valor máximo apontado na tabela. Evidencia-se que o valor médio dos empréstimos aos controladores é significativamente menor que a quantia repassada a outros indivíduos ou organizações, não designados como controladores, enquadrados como Empréstimos contraídos por elementos diversos (EMPD). Tal comprovação pode sugerir a manipulação das demonstrações contábeis, de modo a disfarçar transferências de valores aos controladores, corroborando com o argumento de Jiang, Lee e Yue (2010) de que a fim de esconder os empréstimos em favor dos controladores, tais operações podem ser alocadas em contas genéricas.

Percebe-se também, pela visualização da média da variável Acionista Controlador (AC), 66,42\%, que se refere ao percentual de ações ordinárias pertencentes aos controladores, que os dados da amostra corroboram com as evidências existentes na literatura de alta concentração de propriedade no cenário brasileiro (MARQUES, GUIMARÃES, PEIXOTO, 2015; NEVES, 2015).

\subsection{Análise Fatorial}

Embora a expectativa de uma maior correlação entre as variáveis, uma vez que elas são apontadas pela literatura como proxies de expropriação não tenha sido confirmada, como evidenciado pela

Tabela 1 Estatística Descritiva das variáveis integrantes dos índices

\begin{tabular}{c|c|c|c|c|c}
\hline Variável & Obs. & Média & Desvio-padrão & Mínimo & Máximo \\
\hline EMPC & 996 & 12042,8900 & 111578,7000 & 0 & 2217682 \\
\hline EMPD & 996 & 117582,6000 & 707378,3000 & 0 & $1,06 \mathrm{E}+07$ \\
\hline TPR & 996 & $1,54 \mathrm{E}+09$ & $1,34 \mathrm{E}+10$ & 0 & $2,81 \mathrm{E}+11$ \\
\hline DIV & 996 & 0,0081 & 0,0180 & 0 & 0,1281 \\
\hline DVFC & 996 & 0,3092 & 0,4624 & 0 & 1 \\
\hline AC & 996 & 66,4222 & 19,9497 & 14,6 & 100 \\
\hline ESTAT & 996 & 0,0663 & 0,2489 & 0 & 1 \\
\hline ESTRANG & 996 & 0,0422 & 0,2011 & 0 & 1 \\
\hline INTANG & 996 & 1758,9070 & 30352,2100 & 0 & 891785 \\
\hline
\end{tabular}

Fonte: Elaboração própria 
Tabela 2 Correlação entre as variáveis

\begin{tabular}{c|c|c|c|c|c|c|c|c|c}
\hline & EMPC & EMPD & TPR & DIV & DVFC & AC & ESTAT & ESTRANG & INTANG \\
\hline EMPC & 1,0000 & & & & & & & & \\
\hline EMPD & 0,0070 & 1,0000 & & & & & & & \\
\hline TPR & 0,0140 & 0,5193 & 1,0000 & & & & & & \\
\hline DIV & 0,0232 & 0,0218 & 0,0351 & 1,0000 & & & & & \\
\hline DVFC & 0,0062 & 0,1491 & 0,1263 & 0,1445 & 1,0000 & & & & \\
\hline AC & 0,0627 & 0,0347 & 0,0550 & 0,0061 & 0,2766 & 1,0000 & & & \\
\hline ESTAT & 0,0027 & 0,3105 & 0,2963 & 0,0710 & 0,2410 & 0,0122 & 1,0000 & & \\
\hline ESTRANG & 0,0110 & 0,0100 & 0,0037 & 0,0104 & 0,1404 & 0,0226 & 0,0559 & 1,0000 & \\
\hline INTANG & 0,0063 & 0,1626 & 0,0051 & 0,0140 & 0,0284 & 0,0873 & 0,0154 & $-0,0122$ & 1,0000 \\
\hline
\end{tabular}

Fonte: Elaboração própria

Tabela 2, a utilização da técnica de Análise Fatorial foi legitimada pelos valores do KMO $(0,5745)$ e do P-valor no Teste de Bartlett (0,0000) que, segundo Hair et al. (2009) o resultado do Teste de Esfericidade Bartlett estatisticamente significativo ou o índice de medida de adequação da amostra (KMO) superior a 0,5 confirmam associação suficiente para o uso da referida técnica.
Pela observação da Tabela 3, constata-se quais são as variáveis mais importantes para cada um dos índices de risco de expropriação de acionistas minoritários propostos. A justificativa do nome do primeiro índice é que o mesmo apresenta, como mais relevantes em sua formação, as variáveis TPR e EMPD, que são sugeridas pela literatura como indícios de Tunneling, entendido como transferência de riqueza. $\mathrm{O}$ índice 2 foi denominado como poder

Tabela 3 Coeficientes loading das variáveis latentes mais significativas da análise fatorial

\begin{tabular}{c|c|c|c|c}
\hline \multirow{2}{*}{ Variáveis } & Índice 1 & Índice 2 & Índice 3 & Índice 4 \\
\cline { 2 - 5 } & $\begin{array}{c}\text { Transferência de } \\
\text { Riqueza }\end{array}$ & $\begin{array}{c}\text { Poder dos Controla- } \\
\text { dores }\end{array}$ & Intangibilidade & $\begin{array}{c}\text { Empréstimos a Contro- } \\
\text { Iadores }\end{array}$ \\
\hline EMPC & 0,0041 & $-0,1394$ & $-0,3615$ & 0,7527 \\
\hline EMPD & 0,7695 & $-0,2818$ & 0,2228 & 0,0377 \\
\hline TPR & 0,7412 & $-0,3212$ & 0,0083 & $-0,0867$ \\
\hline DIV & $-0,1792$ & $-0,2321$ & 0,4477 & $-0,0558$ \\
\hline DVFC & 0,4854 & 0,6446 & $-0,1393$ & $-0,0361$ \\
\hline AC & 0,0791 & 0,722 & 0,3595 & $-0,0615$ \\
\hline ESTAT & 0,6658 & $-0,0043$ & $-0,1765$ & $-0,1028$ \\
\hline ESTRANG & $-0,1358$ & $-0,3376$ & 0,169 & $-0,4094$ \\
\hline INTANG & 0,116 & 0,0076 & 0,7228 & 0,4947 \\
\hline Variância Explicada & 0,2034 & 0,1498 & 0,1217 & 0,1158 \\
\hline Variância Acumulada & 0,2034 & 0,3532 & 0,4749 & 0,5906 \\
\hline
\end{tabular}

$\mathrm{KMO}=0,5745$ P-valor $=0.0000$ (Teste de Esfericidade de Barttlet)

Fonte: Elaboração própria 
dos controladores por ser composto, principalmente por aspectos relacionados à quantidade de ações ordinárias pertencentes ao acionista controlador e à diferença entre direito de voto e de fluxo de caixa. Os índices 3 e 4, foram nomeados de acordo com a única variável que se mostrou significativa.

Nota-se também que juntos os quatro fatores conseguem explicar 59\% do fenômeno estudado e o índice com maior representatividade na variância explicada é o de Transferência de Riqueza.

Embora a explicabilidade do índice ITR ao fenômeno de expropriação de minoritários fosse maior que os demais (20\%), optou-se em manter os quatro, para verificar no teste realizado a efetividade dos índices propostos, visto a robusta relação das outras variáveis componentes dos índices defendida pela literatura.

\subsection{Risco de expropriação de acionistas minoritários e Governança Corporativa}

A literatura sugere que quanto maior o nível de governança corporativa, menor os índices de expropriação de acionistas minoritários. Objetivando verificar tal afirmativa, segregou-se os índices de risco de expropriação em relação aos níveis de governança corporativa, conforme demonstrado na Tabela 4.

A Tabela 5, referente ao teste de Normalidade de Jarque-Bera mostra que a maior parte dos índices, quando separados em relação ao nível de governança, não apresenta normalidade. A normalidade somente é percebida ao nível de $1 \%$ de significância, em relação ao IPC para o nível de governança N2. A ausência de normalidade dos índices justifica a verificação de existência de diferenças significativas entre os mesmos, segregados através dos níveis de governança corporativa ao qual pertencem, através do teste não paramétrico de Mann-Whitney.

Tabela 4 Estatística Descritiva dos Índices segregados pelo Nível de Governança

\begin{tabular}{|c|c|c|c|c|c|c|}
\hline \multirow{2}{*}{\multicolumn{2}{|c|}{ Níveis de Governança }} & \multicolumn{5}{|c|}{ Medidas } \\
\hline & & \multirow{2}{*}{$\frac{\text { Obs. }}{360}$} & \multirow{2}{*}{$\frac{\text { Média }}{0,0517}$} & \multirow{2}{*}{$\frac{\text { Desvio - padrão }}{1,4932}$} & \multirow{2}{*}{$\begin{array}{c}\text { Mínimo } \\
-0,5454\end{array}$} & \multirow{2}{*}{$\frac{\text { Máximo }}{14,8465}$} \\
\hline \multirow{4}{*}{ 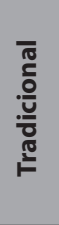 } & ITR & & & & & \\
\hline & IPC & 360 & 0,3953 & 1,0106 & $-2,3553$ & 2,1221 \\
\hline & IINT & 360 & $-0,1091$ & 0,4832 & $-1,6357$ & 1,9192 \\
\hline & IEMPC & 360 & $-0,0780$ & 0,6531 & $-3,4236$ & 0,8980 \\
\hline \multirow{4}{*}{$\bar{z}$} & ITR & 120 & 0,4562 & 0,8768 & $-0,4278$ & 3,8592 \\
\hline & IPC & 120 & 0,7965 & 0,6713 & $-3,1761$ & 1,8441 \\
\hline & IINT & 120 & $-0,3468$ & 0,4226 & $-1,4521$ & 1,2339 \\
\hline & IEMPC & 120 & 0,3215 & 1,4447 & $-0,7774$ & 15,7745 \\
\hline \multirow{4}{*}{$\mathfrak{N}$} & ITR & 51 & 0,1439 & 0,7538 & $-0,5219$ & 2,8390 \\
\hline & IPC & 51 & 0,8673 & 0,7953 & $-1,7777$ & 3,6261 \\
\hline & IINT & 51 & 0,7809 & 3,7860 & $-1,4131$ & 24,7670 \\
\hline & IEMPC & 51 & 0,2470 & 0,6976 & $-0,7503$ & 4,5100 \\
\hline \multirow{4}{*}{$\sum$} & ITR & 433 & $-0,1599$ & 0,2722 & $-0,4942$ & 1,5174 \\
\hline & $I P C$ & 433 & $-0,6569$ & 0,6396 & $-4,9413$ & 1,5276 \\
\hline & IINT & 433 & 0,0742 & 0,5066 & $-0,8899$ & 2,5761 \\
\hline & IEMPC & 433 & $-0,0399$ & 1,1242 & $-2,4111$ & 13,9561 \\
\hline
\end{tabular}

Fonte: Elaboração própria 
Tabela 5 Teste de Normalidade de Jarque-Bera dos Índices de Risco de Expropriação

\begin{tabular}{c|c|c|c|c}
\hline \multirow{2}{*}{$\begin{array}{c}\text { Níveis de } \\
\text { Governança }\end{array}$} & \multicolumn{4}{|c}{ P - valor } \\
\cline { 2 - 5 } & ITR & IPC & IINT & IEMPC \\
\hline Tradicional & 0.0000 & 0.0000 & 0.0000 & 0.0000 \\
\hline N1 & 0.0000 & 0.0000 & 0.0021 & 0.0000 \\
\hline N2 & 0.0000 & 0.0112 & 0.0000 & 0.0000 \\
\hline NM & 0.0000 & 0.0000 & 0.0000 & 0.0000 \\
\hline
\end{tabular}

Fonte: Elaboração própria

A análise da Tabela 6, considerando os níveis de 1,5 e $10 \%$ de significância, permite verificar a existência de diferenças significativas entre os níveis de governança Tradicional e N1 e entre N1 e Novo Mercado, em relação a todos os índices. A comparação do nível Tradicional com o N2 fornece existência de diferenças significativas entre os índices 1, 2 e 4, observando os níveis de significância de 5 e 10\%. Quando comparado o nível Tradicional com o Novo Mercado (NM) somente o ITR não apresenta diferença significativa. A comparação de N1 e N2 evidencia diferença significativa entre os índices 1 e 3 apenas. Ao analisar o P-valor da comparação de $\mathrm{N} 2$ e NM tem-se os índices 1, 2 e 4 estatisticamente significativos.

Tabela 6 Teste de médias de Mann-Whitney dos Índices de Risco de Expropriação

\begin{tabular}{c|c|c|c|c}
\hline \multirow{2}{*}{$\begin{array}{c}\text { Niveis de } \\
\text { Governança }\end{array}$} & \multicolumn{4}{|c}{ P - valor } \\
\cline { 2 - 5 } & ITR & IPC & IINT & IEMPC \\
\hline Tradic. vs N1 & $0.0000^{* * *}$ & $0.0000^{* * *}$ & $0.0000^{* * *}$ & $0.0000^{* * *}$ \\
\hline Tradic. vs N2 & $0.0139^{* *}$ & $0.0009^{* * *}$ & 0.4893 & $0.0043^{* * *}$ \\
\hline Tradic. vs NM & 0.7456 & $0.0000^{* * *}$ & $0.0000^{* * *}$ & $0.0004^{* * *}$ \\
\hline N1 vs N2 & $0.0000^{* * *}$ & 0.5478 & $0.0045^{* * *}$ & 0.6779 \\
\hline N1 vs NM & $0.0000^{* * *}$ & $0.0000^{* * *}$ & $0.0000^{* * *}$ & $0.0000^{* * *}$ \\
\hline N2 vs NM & $0.0048^{* * *}$ & $0.0000^{* * *}$ & 0.3448 & $0.0000^{* * *}$ \\
\hline
\end{tabular}

As significâncias estatísticas dos testes são representadas através da seguinte simbologia:

${ }^{*} 10 \%$; ${ }^{* *} 5 \%$; ${ }^{* * *} 1 \%$.

Fonte: Elaboração própria

Com a confirmação de diferenças significativas, pode-se concluir, pelas evidências da Tabela 4, considerando o ITR, que o risco de expropriação de acionistas minoritários reduz à medida que aumenta o nível de governança, com exceção do Tradicional, que possui valor médio do risco de expropriação menor que N2. No IPC, como não se rejeitou a hipótese nula do teste de que as médias são iguais entre N1 e $\mathrm{N} 2$, e portanto, não se pode inferir que o risco de expropriação das empresas do $\mathrm{N} 2$ seria maior que o das empresas do N1, mas pode-se dizer que a expectativa de minimização gradativa do risco de expropriação à medida que se aumenta o nível de governança pode ser evidenciada na comparação dos valores médios de N2 e Novo Mercado.

Analisando o IINT, a relação entre o segmento Tradicional e o N2 e entre N2 e Novo Mercado não possuem diferença significativa. $\mathrm{ON} 1$ apresenta risco de expropriação menor que todos os demais níveis.

O IEMPC somente não possui diferença significativa na comparação entre os N1 e N2 e se comportou de maneira análoga ao ITR, demonstrando, exceto no Tradicional, que o risco de expropriação de acionistas minoritários diminui na proporção que aumenta o nível de governança.

Tais evidências permitem confirmar a relação negativa entre risco de expropriação e governança corporativa apontada por Jiang e Peng (2011) que destacam a adoção de boas práticas de governança como instrumento de combate aos abusos dos controladores.

\section{CONCLUSÃO}

Considerando a relação inversa da expropriação de acionistas minoritários e Governança Corporativa uma vez que, segundo Brandão e Crisóstomo (2015), o sistema de governança se apresenta como instrumento limitador de abusos de acionistas controladores, esta pesquisa objetivou investigar se os diferenciados níveis de Governança Corporativa impactam na redução/aumento do risco de expropriação de acionistas minoritários das empresas listadas na B3 no período de 2010 à 2016.

Para atingir tal meta, foi feito um levantamento na literatura nacional e internacional para que a análise se baseasse em variáveis já utilizadas para mensurar a expropriação de minoritários. As proxies 
encontradas foram relacionadas e agrupadas, através de Análise Fatorial, em quatro índices denominados: Índice de Transferência de Riqueza (ITR), de Poder dos Controladores (IPC), de Intangibilidade (IINT) e de Empréstimos a Controladores (IEMPC). De posse desse ranking de risco de expropriação de acionistas minoritários foi realizado o Teste de Médias não paramétrico de Mann-Whitney para verificar a existência de diferenças significativas entre os índices e os diferenciados níveis de governança corporativa.

Os principais achados deste estudo se relacionam ao comportamento do risco de expropriação de acionistas minoritários em cada um dos níveis de governança corporativa e também na classificação como Tradicional.

O resultado do teste de Normalidade de Jarque- Bera rejeita, aos níveis de significância de 5 e 10\%, a hipótese nula da presença de distribuição normal do risco de expropriação em cada nível de governança. Logo, o teste de Médias de Mann-Whitney foi utilizado para verificar a existência de diferenças significativas do risco de expropriação na comparação dos níveis de governança. As evidências deste trabalho do risco de expropriação no nível Tradicional ser menor que no nível 1, exceto no IINT, corroboram com a afirmação de Forti, Peixoto e Alves (2015) de que as empresas não enquadradas em níveis diferenciados da Bovespa podem utilizar boas práticas de governança.

A hipótese nula do teste de médias, para o índice ITR foi rejeitada nas comparações de N1 e N2, N1 e Novo Mercado e N2 e Novo Mercado. Conclui-se pelo exame da Estatística Descritiva segregada nos níveis de governança, que neste índice, o risco de expropriação diminui à medida que aumenta o nível. O mesmo se observa na análise do índice ICP, onde se comprova a redução do risco na comparação do nível 2 e o Novo Mercado. Quanto ao índice IEMPC, que não apresentou diferença entre N1 e N2, pode-se inferir que o risco de expropriação também decresce com a elevação do nível de governança.

Pelo exposto no confronto do ranking de risco de expropriação dos minoritários e os níveis de governança corporativa, pode-se afirmar, conforme destacado por Camargo (2012) que melhores práticas de governança são relevantes na minimização do risco de desvio de riquezas pelos controladores.
As limitações deste estudo se relacionam ao enquadramento das empresas nos respectivos níveis de governança, uma vez que se seguiu o exposto na B3, que espelha o estado atual em todos os anos, ou seja, não foram observadas as mudanças de níveis.

Como futuras linhas de pesquisa sobre o tema sugere-se verificar a existência de outras proxies relacionadas à expropriação de minoritários a fim de comprovar a robustez dos índices propostos e avaliar se o risco de expropriação aumentou/diminuiu em empresas que tenham migrado de nível de governança.

\section{REFERÊNCIAS}

BARBEDO, Claudio Henrique; SILVA, Eduardo Camilo Da; LEAL, Ricardo Pereira Câmara. Probabilidade de informação privilegiada no mercado de ações, liquidez intra-diária e níveis de governança corporativa. Revista Brasileira de Economia, v. 63 , n. 1, p. 51-62, 2009.

BRANDÃO, Isac de Freitas; CRISÓSTOMO, Vicente Lima. Concentração de propriedade e qualidade da governança da empresa brasileira. Revista Brasileira de Finanças, v. 13, n. 3, p.438-469. 2015.

CAMARGO, André Antunes Soares de. Transações Entre Partes Relacionadas: um desafio regulatório complexo e multidisciplinar. Tese de Doutorado em Direito Comercial, Universidade de São Paulo, SP, Brasil. 2012.

CAMARGOS, Marcos Antônio de; BARBOSA, Francisco Vidal. A adoção de práticas diferenciadas de governança corporativa beneficia o acionista e aumenta a liquidez acionária? REGE. Revista de Gestão, v. 17, n. 2, p. 189, 2010.

CAVAlCANTE, Mônica Clark Nunes; DE LUCA, Márcia Martins Mendes. Controladoria como instrumento de governança no setor público. Revista de Educação e Pesquisa em Contabilidade (REPeC), v. 7, n. 1, 2013. 
DE LUCA, Márcia Martins Mendes; MARTINS, Luana Carlos; MAIA, Anna Beatriz Grangeiro Ribeiro; COELHO, Antonio Carlos Dias. Os mecanismos de auditoria evidenciados pelas empresas listadas nos níveis diferenciados de governança corporativa e no novo mercado da Bovespa. Contabilidade Vista \& Revista, v. 21, n. 1, p. 101-130, 2010.

DO MONTE, Paulo Aguiar; REZENDE, Isabelle Carlos Campos; TEIXEIRA, Gibran da Silva; BESSARIA, Cassio da Nobrega. Existe relação entre Governança Corporativa e volatilidade? Um estudo a partir da formação de carteiras. Contabilidade Vista \& Revista, v. 21, n. 2, p. 15-44, 2010.

DOIDGE, Craig et al. Private benefits of control, ownership, and the cross-listing decision. The Journal of Finance, v. 64, n. 1, p. 425-466, 2009.

FACCIO, Mara; LANG, Larry H.P; YOUNG, Leslie. Dividends and expropriation. American Economic Review, v. 91, n. 1, p. 54-78, 2001.

FORTI, Cristiano Augusto Borges; PEIXOTO, Fernanda Maciel; ALVES, Denis Lima. Determinant factors of dividend payments in brazil. Revista Contabilidade \& Finanças, v. 26, n. 68, p. 167-180, 2015.

FITRI, Nurul; IRIANTO, Gugus; MARDIATI, Endang. The effect of ownership structure on the expropriation risk. International Business Management, v. 11, n. 2, p. 392-396, 2017.

HAIR, Joseph F.;BLACK, William C.; BABIN, Barry J.; ANDERSON, Rolph E.; TATHAM, Ronald L.Análise multivariada de dados. Porto Alegre: Bookman, 2009.

HIMMELBERG, Charles P.; HUBBARD, R. Glenn; PALIA, Darius. Understanding the determinants of managerial ownership and the link between ownership and performance. Journal of Financial Economics, v. 53, n. 3, p. 353-384, 1999.
INSTITUTO BRASILEIRO DE GOVERNANÇA CORPORATIVA. Código das melhores práticas de governança corporativa. 5. ed. São Paulo: 2014.

JAVID, Attiya Y.; IQBAL, Robina. Ownership concentration, corporate governance and firm performance: Evidence from Pakistan. The Pakistan Development Review, v. 47, n. 4-II, p. 643-659, 2008.

JENSEN, Michael C.; MECKLING, William H. Theory of the firm: Managerial behavior, agency costs and ownership structure. Journal of Financial Economics, v. 3, n. 4, p. 305-360, 1976.

JIANG, Guohua; LEE, Charles M.C.; YUE, Heng. Tunneling through intercorporate loans: The China experience. Journal of Financial Economics, v. 98, n. 1, p. 1-20, 2010.

JIANG, Yi; PENG, Mike W. Principal-principal conflicts during crisis. Asia Pacific Journal of Management, v. 28, n. 4, p. 683-695, 2011.

LA PORTA, Rafael; SILANES, Florencio Lopes de; SHLEIFER, Andrei; VISHNY, Robert W. Agency problems and dividend policies around the world. The Journal of Finance, v. 55, n. 1, p. 1-33, 2000.

LEAL, Ricardo Pereira Câmera; SILVA, André Luiz Carvalhal da; VALADARES, Silvia Mourthé. Estrutura de controle das companhias brasileiras de capital aberto. Revista de Administração Contemporânea, v. 6, n. 1, p. 7-18, 2002.

LUO, Yongli; JACKSON, Dave O. CEO compensation, expropriation, and the balance of power among large shareholders. Advances in Financial Economics, v.5, p. 195-238, 2012.

MALACRIDA, Mara Jane Contrera; YAMAMOTO, Marina Mitiyo. Governança corporativa: nível de evidenciação das informações e sua relação com a volatilidade das ações do Ibovespa. Revista Contabilidade \& Finanças, v. 17, p. 65-79, 2006. 
MARQUES, Thiago de Avila; GUIMARÃES, Thayse Machado; PEIXOTO, Fernanda Maciel. A concentração acionária no Brasil: análise dos impactos no desempenho, valor e risco das empresas. Revista de Administração Mackenzie (Mackenzie Management Review), v. 16, n. 4, p. 100-133. 2015.

MINGOTI, Sueli Aparecida. Análise de dados através de métodos de estatística multivariada: uma abordagem aplicada. Belo Horizonte: UFMG, 2005.

NARDI, Paula Carolina Ciampaglia; NAKAO, Sílvio Hiroshi. Impacto da Entrada nos Níveis Diferenciados de Governança Corporativa sobre a Imagem Institucional das Empresas. Contabilidade Vista \& Revista, v. 19, n. 2, p. 85-111. 2008.

NEVES, Patrícia Antonacci Conflito entre acionistas, Concentração Acionária, Governança Corporativa e Valor da Empresa: Um estudo nas companhias abertas brasileiras. Dissertação de Mestrado em Ciências Contábeis, Universidade Federal de Minas Gerais, Belo Horizonte, MG, Brasil. 2015.

PROCIANOY, Jairo Laser; VERDI, Rodrigo S. Adesão aos Novos Mercados da BOVESPA: Novo Mercado, Nível 1 e Nível 2 - Determinantes e Consequências. Revista Brasileira de Finanças, v. 7, n. 1, p. 107-136. 2009.

RENCHER, Alvin C. Methods of Multivariate Analysis. 2. ed. Hoboken: John Wiley \& Sons, 2002.

RENDERS, Annelies; GAEREMYNCK, Ann. Corporate governance, principal-principal agency conflicts, and firm value in European listed companies. Corporate Governance: An International Review, v. 20, n. 2, p. 125-143, 2012.

SILVA, Karina Lima da; OLIVEIRA, Marcelle Colares; MENDES, Marcia Martins de; ARAUJO, Osorio Cavalcante. A Implementação dos Controles Internos e do Comitê de Auditoria Segundo a Lei SOX: o Caso Petrobras. Contabilidade Vista \& Revista, v. 20, n. 3, p. 39-63, 2009.
SILVEIRA, Alexandre Di Miceli da. Governança corporativa e estrutura de propriedade: determinantes e relação com o desempenho das empresas no Brasil. Tese de Doutorado em Administração, Universidade de São Paulo, São Paulo, SP, Brasil, 2004.

TAM, On Kit; TAN, Monica Guo-Sze. Ownership, governance and firm performance in Malaysia. Corporate Governance: An International Review, v. 15, n. 2, p. 208-222, 2007.

YOUNG, Michael N.; PENG, Mike W.; AHLSTROM, David; BRUTON, Garry D.; JIANG, Yi. Corporate governance in emerging economies: A review of the principal-principal perspective. Journal of management studies, v. 45, n. 1, p. 196-220, 2008. 